\title{
Estereotipos y vulnerabilidad. Los inundados de Resistencia
}

Nidia Pifieyro

\section{Introducción}

Resistencia es la ciudad capital de la Provincia del Chaco y está ubicada al Nordeste de Argentina. Fue fundada hacia 1878 sobre un terreno anegadizo y su patrón de poblamiento la vuelve progresivamente más vulnerable. Cada vez que el río crece o llueve en demaśa se vive un escenario de emergencia en el que los inundados cobran protagonismo en los canales de televisión, en la prensa escrita y en la radio. Nos interesa este grupo por ser un ejemplo muy claro de como los medios pueden construir y alimentar una serie de procesos funcional a un esquema de desarrollo local deficitario.

A partir de los criterios de análisis expuestos por Lavell (2000), quien considera a los desastres como 'cuentas negativas de desarrollo' intentaremos demostrar que la percepción estereotipada de los actores afectados obstruye el proceso de construcciones alternativas de diagnósticos, definiciones y propuestas de solución para disminuir el riesgo y la vulnerabilidad frente a la amenaza de las inundaciones. Creemos que los afectados por las inundaciones del Gran Resistencia son presentados por los medios de comunicación nacionales como protagonistas de un suceso excepcional, la crecida y desborde de los ríos. En ese marco, el inundado es representado con una serie de rasgos que tienden a resaltar su carácter carenciado como consecuencia de la inundación. Los relatos y descripciones son acompaffados de un fuerte llamado a la solidaridad-que invariablemente es contestado por la audiencia y se traduce en donaciones provenientes de diversos puntos de la nación-. Cuando la calamidad deja de ser noticia los medios nacionales dejan de cubrir la situación, que pasa, en los hechos, a una segunda etapa: la interacción del grupo afectado con los otros miembros de la comunidad de Resistencia. En este contexto sociocultural los inundados son evaluados negativamente por el resto de la gente. Esta percepción está sujeta a las cargas valorativas de los estereotipos que unos tienen de los otros y de la posición que ocupan en el sistema productivo. Como resultado de esta conceptualización, surge la justificación del estado de su indigencia eventual y de su situación social histórica. Esta estigmatización del grupo afectado descuenta la posibilidad de enfrentar la problemática con mecanismos de participación comunitaria de manera que el repertorio (de los diagnósticos y soluciones) que se imponen provienen exclusivamente de la administración estatal.

\section{Conceptos clave}

Que los inundados existen es algo que ningún habitante de la Argentina dudaría en admitir aún cuando no conociera personalmente a ningún afectado. Es aquí donde comienza nuestra búsqueda. ¿Es posible que los medios nacionales hayan instalado cierta imagen sobre la inundación y sobre el grupo? ¿Es lo mismo un 'afectado por las inundaciones' que un 'inundado'? ¿Qué percepción tiene la comunidad local sobre los inundados? ¿Qué aspectos de los afectados contiene el concepto 'inundado'? ¿El inundado es un estereotipo? ¿Es posible la solidaridad con un grupo estereotipado? El empleo de los conceptos de representación, 
estereotipo, imagen, deben ser interpretados en el marco de la semiótica aplicada a los estudios de comunicación de masas ${ }^{I}$ de la que hemos tomado también las nociones de construcción de acontecimientos, ideología e industria cultural.

En los conceptos de desastre, emergencia, vulnerabilidad y riesgo seguimos a Lavell (1994); para los de 'percepción de riesgo' y 'nuevo actor colectivo' recurriremos a Poggiese (2000).

\section{2.a. Inundados e inundación, identidad y acontecimiento}

Creemos que : los inundados comparten (o están sometidos a) una serie de circunstancias comunes que hacen posible delinear una identidad Entendiendo, con Geerz (1996), que tal concepto alude una construcción imaginaria definida con relación a un contexto cultural particular que permite que el individuo (el grupo, o la comunidad) se diferencie de las demás personas -de "los otros"-. Esta identidad puede ser considerada "social" ya que es coproducida por los actores en situaciones de interacción, se construye en un continuo y complejo entramado de relaciones en el seno de una estructura social y se manifiesta por medio de valores, pautas, criterios y visiones comunes entre los individuos. La identidad social de un grupo presenta como factor importante el hecho de que es contingente, que no está dada de una vez y para siempre si no que está condicionada por los cambios históricos y las características del espacio donde reside, de la comunidad a la que pertenece. Más allá de que la idea de pertenencia a ese grupo surja de manera intermitente como resultado de la convergencia de factores exógenos (el clima, por ejemplo), existen otros factores (geográficos, sociales, políticos) que le dan cohesión y continuidad en el tiempo y en el espacio.

Las inundaciones provocadas por los desbordes de los cursos fluviales en Resistencia son tan antiguas como la ciudad misma. Las primeras grandes inundaciones datan de 1905. Hacia 1966, la crecida del Paraná puso en situación de emergencia a toda la población de Barranqueras y Puerto Vilelas y en estado de alerta a gran parte de los habitantes de la ciudad capital. Por la cantidad de damnificados, por las pérdidas económicas y por la invasión de las aguas a la zona capitalina, es recordada por los resistencianos como la 'Inundación Grande'. Pero, aunque la espectacularidad de aquella inundación no haya sido superada por las recientes crecidas (cada vez que surge la hipótesis de catástrofe son comparadas las marcas) tenemos la sensación de que: i) la calamidad es mayor, ii) hay más afectados y iii) la existencia de los grupos de inundados es tan inevitable como natural. Es posible que estas tres percepciones de la situación no obedezcan a observaciones directas de la realidad o la experiencia.

Es probable que el drama real que acarrean las inundaciones esté siendo fabricado por los medios y, en ese proceso, la imagen que tenemos como espectadores acerca del suceso en sí mismo sea producto de una serie de estrategias mediáticas conocida como "construcción de acontecimiento". Al respecto Aparici (1996:40) señala que:

Aunque los documentos de la prensa no son reales pueden modelar nuestras actitudes, conductas e ideas sobre el mundo. (...) Si no hemos tenido una experiencia de primera mano con personas, lugares o cosas $\mathrm{y}$, sin embargo, tenemos la sensación de que sabemos algo a cerca

\footnotetext{
${ }^{1}$ Especialmente, Eco, U. (1981;Edic. original 1976): Tratado de Semiótica General; Lumen; Barcelona; Verón, E. (1983) Construir el acontecimiento, Gedisa.; y Aparici, R. (1996) La revolución de los medios audiovisuales; Ed. La torre, Madrid.
} 
de todo ello basándonos en las informaciones de los medios, entonces es que los medios nos han construido una forma de realidad.

Tenemos suficientes motivos para sostener que el relato y la descripción que los medios hacen a partir de, un hecho real como lo es el de la crecida de las aguas o las abundantes lluvias y sus consecuencias dafinas para los habitantes tienen una determinada teoría social subyacente. Atorresi (1996:119) afirma que los acontecimientos que circulan en los mèdios:

suponen alguna teoria en tanto presumen: sistemas de conceptos implicados en la explicación de las cosas, en la conexión de unos acontecimientos con otros, en su ubicación dentro del contexto de estructuras y causas. (...)No existen hechos "crudos", ininterpretados o ateóricos (...) En la prensa, se juzga el acontecimiento como miembro de una clase, desde una determinada teoría del orden social $y$, de este modo, lo particular entre la red de relaciones que las cosas de esa clase tienen con cosas de otras clases.

Además de ser expresiones de una teoría social dada, es caracteristico que los productos mediáticos que conocemos sean el resultado de un proceso de selección cuyos criterios son sumamente especificos. Los mismos tienden a generar una imagen natural y verosimil y a sustituir el conocimiento empirico.

El relato de las inundaciones y las descripciones de los afectados del Nordeste se han convertido en un clásico de la televisión y los medios gráficos a nivel nacional porque la calamidad y el dolor pertenecen a una clase de acontecimientos sociales categorizados como excepcionales en el imaginario colectivo. Justamente, lo que marca la configuración de los acontecimientos en general es su relación de ruptura con la normalidad. Un repaso sobre las condiciones para que un hecho se convierta en acontecimiento nos dan la clave para comprender los motivos por los cuales las inundaciones son noticia.

Las inundaciones como suceso tiene los elementos necesarios para convertirse en acontecimiento porque además de ser algo excepcional, es políticamente relevante para la dinámica social de la comunidad argentina en tanto afecta a un sector social determinado -si bien minoritario en relación a su acceso al poder- que podría desencadenar desequilibrios en el sistema social en caso de no ser asistidos en la emergencia. Este carácter de 'emergente' es el otro componente indispensable para ser procesado como producto de la industria cultural como 'actualidad'. Es un hecho que contiene en sí mismo un límite de saturación: cuando bajan las aguas, la inundación deja de ser noticia y es reemplazado en la agenda periodística por otro suceso excepcional, relevante y variable rápidamente. Esto en sí mismo no sería de gravedad extrema si el desastre se configurara como permanente, al menos, en la agenda de gobierno.

Es evidente que los medios no pueden -ni les interesa- presentar todos los hechos relevantes, extraordinarios y rápidamente variables. Existe un proceso de selección de acontecimientos basado en su valor como noticia. Las decisiones sobre quién y qué se va a mostrar; qué gente y qué suceso, cómo esa gente y esos sucesos serán mostrados dependen en gran medida de "su interés como noticia, la familiaridad del espectador, las convenciones, costumbres, su valor como entretenimiento, motivo, punto de vista. "(Aparici, 1996:224)

Estos parámetros determinan la repetición de un repertorio de temas relativamente escueto. Así, el tema de las inundaciones tesponde al criterio de selección que dice que es 
'noticiable' todo suceso que a través de su contenido configuren la violencia, la agresividad, el dolor, la muerte como pruebas documentales del estar constantemente amenazado o sometido a la fatalidad del destino y, sin embargo hallarse a salvo.

En relación con esta forma de interpretar y mostrar al afectado y al evento es llamativa la correspondencia que hay con cierta manera de diagnosticar los desastres y persuadir a la población de que se está gestionando la reconstrucción cuando lo que se tiende es a agravar las condiciones de vulnerabilidad.

\section{2.b. Desastre, riesgo y vulnerabilidad}

Para Lavell (2000) el concepto de desastre debiera incluir el hecho de que es la misma sociedad y no los eventos fisicos, -naturales o no, con los cuales se asocian, y con los cuales, en muchas oportunidades, se confunden- su causa principal y más importante. De esta manera, el autor entiende que un desastre, claramente, no es el evento físico (un sismo o huracán) sino los efectos que éstos producen en la sociedad. Estos eventos son necesarios para que el desastre ocurra pero debe haber como requisito una sociedad o un subconjunto de la sociedad vulnerable a sus impactos; una sociedad que por su forma particular de desarrollo resulte incapacitada para recuperarse autónomamente de los impactos.

Desde esta optica el concepto de desastre es inseparable de los de desarrollo y vulnerabilidad. Esta interpretación hace notar que los desastres son el producto de procesos de transformación y crecimiento de las sociedades incapaces de manejar una adecuada relación con el ambiente natural y construido que le da sustento. Son, como algunos lo han expresado, problemas no resueltos del desarrollo, y la vulnerabilidad existente es una manifestación de déficit en el desarrollo.

Para decirlo en otros términos: los desastres son más que la causa de la vulnerabilidad, el motivo que desnuda una situación de desequilibrio histórico (no eventual ni aislado) producto de la modalidad de crecimiento que caracteriza a los pueblos occidentales ${ }^{2}$. Este modelo de crecimiento asume como un componente propio el sometimiento de la sociedad al riesgo.

El riesgo, que constituye una condición latente para cualquier sociedad, es también un concepto más complejo del que habitualmente se admite. En estrecha relación con la estrategia mediática de la construcción de acontecimientos, el concepto de riesgo sufre en el discurso dominante de la globalización un sesgo tendiente a presentar como natural el hecho de vivir amenazados. Esta manera de presentar la amenaza obvia la alusión de los riesgos que el propio hombre genera aumentando la probabilidad de daños y desastres en aras del proceso de crecimiento económico.

2 En Lavell, A. (2000) "Desastres y desarrollo, hacia un entendimiento de las formas de construcción social de un desastre: el caso del Hurachn Mitch", se explica que este desequilibrio reside en la presunción occidental de que la naturaleza existe para ser dominada y utilizada, la cual está en la base de la llamada crisis ambiental de la actualidad. Otra parte de la explicación reside en el imperativo de las modalidades de crecimiento económico, en boga durante las últimas décadas, pero esencialmente desde el inicio de la Revolución Industrial, tipificada entre otras cosas por la acelerada transformación de la sociedad de una relación inmediata con la naturaleza, en una donde dominan las relaciones mediatas; la urbanización desecologizada; la búsqueda de la ganancia a corto plazo; el empobrecimiento de grandes masas de la población, su marginalización en el territorio y su inseguridad frente a la vida cotidiana. La sociedad moderna es la nueva sociedad del riesgo. 


\section{La lectura de los desastres}

La propuesta que hace la nueva literatura de los desastres guarda una relación muy estrecha con la lectura e interpretación de los medios masivos. El texto de Lavell enfatiza, entre otras, las siguientes cuestiones:

A) Un análisis serio de la problemática de los desastres y el desarrollo debe utilizar un marco de análisis temporal que garantice que el "ciclo de vida" completo de los desastres, sea considerado, y no solamente las implicaciones que éstos tienen para el desarrollo, una vez sucedidos.

B) La desmedida atención puesta en los impactos que los desastres pueden tener en el desarrollo futuro, sirve como una distracción en cuanto el problema fundamental, el cual se refiere a la forma en que las mismas modalidades de desarrollo condicionan la concreción y existencia de los desastres.

C) El problema principal no es que los desastres tengan impactos negativos en el desarrollo, particularmente cuando las pérdidas asociadas son grandes, comparadas con el tamaño de la economía afectada, sino más bien el problema de fondo, es el tamaño reducido y los niveles bajos de desarrollo de las economías y sociedades afectadas

D) La concentración de las estadísticas y los análisis en los daños y las pérdidas asociadas con los desastres, en el espacio social del daño, soslaya la comprensión cabal del problema del_desastre. Igual importancia debe concederse al análisis del espacio social de la resiliencia o del no daño exhibido en zonas y comunidades inmersas en la escena general del desastre. Mayores lecciones para la reducción futura del riesgo, se aprenden del estudio de la resiliencia y la adaptación mostradas por algunas comunidades, sistemas productivos, e infraestructuras, que por el análisis de las pérdidas sufridas.

Esta nueva perspectiva nos ha hecho pensar en algunas explicaciones para las representaciones que circulan en nuestra ciudad en épocas de inundaciones. Al respecto, este análisis estaría indicándonos que:

A) No es casual que los paisajes mediáticos predilectos de la prensa, cuando de inundaciones se trata, sean las villas periféricas, los albergues atestados de gente, la anécdota de los animales domésticos abandonados, la angustia de las familias disgregadas, el desamparo, etc. Los habitantes de Resistencia sabemos que el agua también afecta a otros sectores de la ciudad como por ejemplo, la zona residencial del Río Negro, donde viven familias de posición socioeconómica diferente y cuyos dramas tienen que ver con cuestiones como las de rescatar una biblioteca $o$ abandonar un vivero. Si los 'rescates en lancha' no son tan frecuentes en la pantalla y en las primeras planas como lo son las penosas filas de carros o automóviles desvencijados, las canoas con un perro en la punta o las peregrinaciones de mujeres con niffos a cuestas en medio del lodo es porque el impacto del evento (su evaluación de los daños) está siendo seleccionada en desmedro de la resiliencia. Lo que la prensa deja de lado es mucho si pensamos en la posibilidad de aprendizaje que vehiculizaría un modelo exitoso de resistencia al desastre. Esta representación de las inundaciones del Gran Resistencia son el resultado de una cuidadosa elaboración que tiende a configurar el escenario propicio para la presentación de los damnificados -que en última instancia son quienes sostienen el acontecimiento. 
B) Esta manera de plasmar una versión de la situación como la única existente (a pesar de las numerosísimas opciones de programas y canales, de publicaciones diarias y periódicas, es dificil no encontrarnos con el mismo tipo de fotografias, relatos y descripciones), responde a la intención de fijar la imagen de los afectados por las aguas como pertenecientes a un grupo social determinado que está pasando por un mal momento y necesita de nuestra ayuda. En términos de la problemática del desarrollo como potenciador de desastre lo que la prensa esquiva es el planteo de la situación de desequilibrio previo a las inundaciones, haciendo hincapié en la emergencia y distrayendo a la población del eje central del conflicto: la modalidad de desarrollo. La solidaridad a la que se exhorta es funcional al no desarrollo del grupo al que se pretende ayudar.

C) Se evalúa al grupo como responsable de sus condiciones reducidas de desarrollo. Las audiencias son grupos de individuos que reaccionan de una manera suficientemente predecible, razón por la cual, los medios cuentan de antemano con la respuesta solidaria que no se hace esperar: las imágenes de camiones cargados de alimentos no perecederos, pañales, calzados, colchones, remedios -cuando no la instantánea de algún presentador 0 político relevante entregando lo recolectado en algún albergue atestado- opera como broche de una historia emotiva con final feliz en la que los medios se muestran a sí mismos como el eslabón esencial para hacer fluir la solidaridad de la gente. Mientras tanto, la inundación en el Chaco pasa a la fase siguiente pero la cobertura mediática se circunscribe en esta etapa a la que realizan las emisoras radiales y los diarios locales. También aquí es notable el cambio que va sufriendo la categorización del acontecimiento con el paso de los días. Podemos advertir la siguiente secuencia: en las primeras jornadas de la emergencia los datos de la crecida, los pronósticos, las declaraciones oficiales, aparecen en primera plana y son ampliadas y abundantemente comentadas en secciones de economía, política o sociales. Es habitual que durante los primeros días los medios televisivos transmitan fuera de programa flashes informativos y que las radios realicen maratones con el fin de mantener al tanto a la población. Una vez que la emergencia es catalogada como 'normal', los espacios van disminuyendo y la clasificación se modifica. La cobertura de la vivencia en los albergues queda relegada en el diario, a la sección 'carta de lectores' y en la radio, a los programas cuya dinámica se basa en los llamados telefónicos de los espectadores. Tanto las cartas de lectores como los llamados al aire ponen de manifiesto un concepto de inundado que contiene, además del de pobreza, otros componentes de tipo evaluativo.

\subsection{El inundado durante la emergencia}

Para hablar de estereotipo es necesario advertir la proximidad que mantiene con el significado de representación, Robyn Quin (1996:224) en su articulo Enfoques sobre el estudio de los medios de comunicación dice que el término

Representación abarca la idea de que ella es de algún modo algo típico o característico de la persona o grupo representado. Cuando una serie limitada de símbolos se presentan repetidamente como algo típico de un grupo, pasamos a la cuestión de la creación de los estereotipos. Esto es una consideración política y social importante para muchos grupos.

Las imágenes con las que se muestra a los afectados en los medios nacionales y en los medios locales (durante la primera etapa) representan a una parte del grupo y no a la totalidad. 
A fuerza de repetición y omnipresencia se establece una homologación entre los afectados y la condición social baja que podría traducirse en la frase 'los inundados son todos pobres'. Sabemos que en realidad los inundados pobres son un subgrupo de todos los inundados. Siguiendo a Robyn Quin, podemos entender el estereotipo como una representación repetida frecuentemente que convierte algo complejo en algo simple causando distorsión en dicho proceso porque se hace más énfasis en algunos aspectos del grupo mientras se ignoran otros.

La complejidad que comporta la existencia de varios sectores geográficos, sociales y culturales implicados en la emergencia es reducida exclusivamente a un sector con caracteristicas socioculturales similares: lo que vemos es un grupo de extracción pobre, cuya insatisfacción de necesidades básicas (vivienda, alimentación, salud, empleo) data de mucho antes de que la inundación produjera la emergencia. Generalmente, son habitantes de las riveras del río o pobladores de los asentamientos próximos a las lagunas. Es importante aquí el papel que juegan tanto la simplificación en la conformación del grupo como la reducción de los aspectos que son tomados para mostrarlos: los inundados son todos pobres, no tienen (pero tampoco tenían antes de la crecida) viviendas dignas, alimentación adecuada, vestido, atención médica y eventualmente empleo. Otra cosa: hacen sus viviendas en lugares históricamente inundables.

Como el estereotipo es un modo de categorizar el mundo real, de darle significado a un aspecto especifico de ese mundo en vez de otro, nos interesa saber de qué manera categorizamos, como habitantes de Resistencia lo que sabemos acerca de los 'inundados'.

Con el objeto de relevar un perfil del concepto de 'inundado' en el habitante de Resistencia realizamos una serie de entrevistas con diferentes actores sociales: una docente de una escuela que recibiera en las últimas crecidas (1998) a un contingente de familias afectadas, un ama de casa del área del Río Negro, un agente de policía del Barrio Guiraldes afectado para el traslado y la vigilancia de un albergue instalado en la E.N.S. $N^{\circ} 73$ del Barrio Llaponagat y un vecino del mismo barrio. Las preguntas que orientaron los relatos tenian que ver con la percepción que dichos actores tenían sobre i) quiénes eran los inundados, ii) qué relación habian tenido con ellos, iii) cómo podian caracterizarlos. El resultado del relevamiento confirma la hipótesis de la instalación de un estereotipo en la conceptualización del inundado. Hay una coincidencia abrumadora en la identificación del grupo (localización geografica y perfil socio económico): los inundados son los que viven a orillas del Rjo Paraná (Vilelas o Barranqueras), en las cercanías del Golf o próximos a Villa Miranda Gallino. Es llamativo que el ama de casa del área residencial del Río Negro haya propuesto una suerte de excepción cuando le dijéramos que su casa estaba en una zona inundable, "Bueno, -dijo- de alli a que yo me considere inundada... Solamente si llueve mucho, crece el Río Negro... No siempre tenemos que salir... Mi marido levanta las cosas al piso de arriba y nosotros vamos a lo de mi mamá". En este relato aparece con claridad la noción de autopercepción como fundamental para la identificación como miembro del grupo. El agente de policía al contar su experiencia en relación con los afectados dejó entrever que muchos de los asistidos no tenían agua en la casa y que de todas formas se hacian trasladar: "Según ellos, eran inundados".

¿Qué es lo que hace que una afectada por las aguas se resista a ser considerada 'inundada' y, a la inversa, que algunos individuos no afectados se arroguen el título de damnificados? 


\begin{abstract}
Algunos fragmentos de las entrevistas sostenidas con la docente y el vecino del Barrio Llaponagat pueden arrojar cierta luz sobre los motivos que a unos lleva a percibirse dentro del grupo y a otros fuera, más allá de el hecho de estar realmente en emergencia.

"Son gente múy humilde, muy carenciada. Eso se nota porque a la hora de repartir la comida las madres pelean por la comida (...) Con la ropa sucede lo mismo",-dice la docente.

El vecino, por separado, caracteriza al grupo con calificativos como "patoteros, irrespetuosos, sucios, sin educación y haraganes", agrega que "no saben agradecer lo que se hace por ellos".

Subrayamos sólo una de las caracteristicas por haber aparecido en tres ocasiones y porque en el relato de la docente el hecho de disputar por la comida o por la ropa se ve 'explicada' por su condición de pobre.

Si tomamos los dos últimos fragmentos es obvio que las caracterizaciones se basan, casi exclusivamente en aspectos negativos. $\mathrm{Si}$ a éste conjunto le sumamos el rasgo de mendacidad deslizado por el agente de policía tenemos una idea bastante clara de por qué hay damnificados que se rehúsan a ser considerados 'inundados'.

El hecho de que cinco personas se refieran a los inundados en esos términos no tendría ninguna relevancia para intentar una generalización. Pero también en los medios locales es posible detectar algunas referencias similares en el marco de quejas, pedidos de intervención policial y opiniones sobre el grupo. Son habituales los episodios relatados en carta de lectores 0 en la radio sobre los destrozos producidos, la falta de higiene, la desidia, la alcoholización o la tendencia a provocar disturbios, atribuida a los inundados alojados en albergues. La presentación sistemática de algunos rasgos sobre un grupo por parte de los medios termina convirtiendo un prejuicio más o menos privado en un concepto compartido colectivamente.

Si tenemos presente que las condiciones de existencia de los medios incluyen, según Eco (1981), una sociedad de tipo industrial suficientemente estratificada y muy rica en contrastes y diferencias; unos canales de comunicación que permiten alcanzar a un círculo indefinido de receptores en situaciones sociologicas distintas $y$, unos grupos productores que elaboran y emiten mensajes con medios industriales; entonces, se comprenderá la extensión que puede llegar a tener un estereotipo. Si a esto le agregamos el hecho de que las representaciones se vehiculizan de un modo instituido (es decir que existen pocas posibilidades de que como individuos tengamos representaciones libres y originales) tenemos suficientes elementos para sospechar que el concepto de 'inundado' es parte de una visión muy generalizada.
\end{abstract}

\title{
3.1.1. Los inundados después de la emergencia
}

Decíamos que, en tanto categorizadores, los estereotipos nos permiten organizar información sobre el mundo. Algunos estereotipos pueden parecer obvios porque son reconocidos por todos. Estos se convierten en un modo natural de pensar, de hablar y de bromear acerca de grupos sociales reales. En época de crecidas, en la comunidad de Resistencia, es natural of́r chanzas con relación a la situación de los hombres albergados. Frases como: 'fulano trabaja de inundado' o 'qué fácil es ser inundado' connotan negativamente a los jefes de familia y es uno de los componentes claves en el proceso de estereotipación del grupo (Robyn Ouin 1996:225) que puede sintetizarse en los siguientes pasos: 


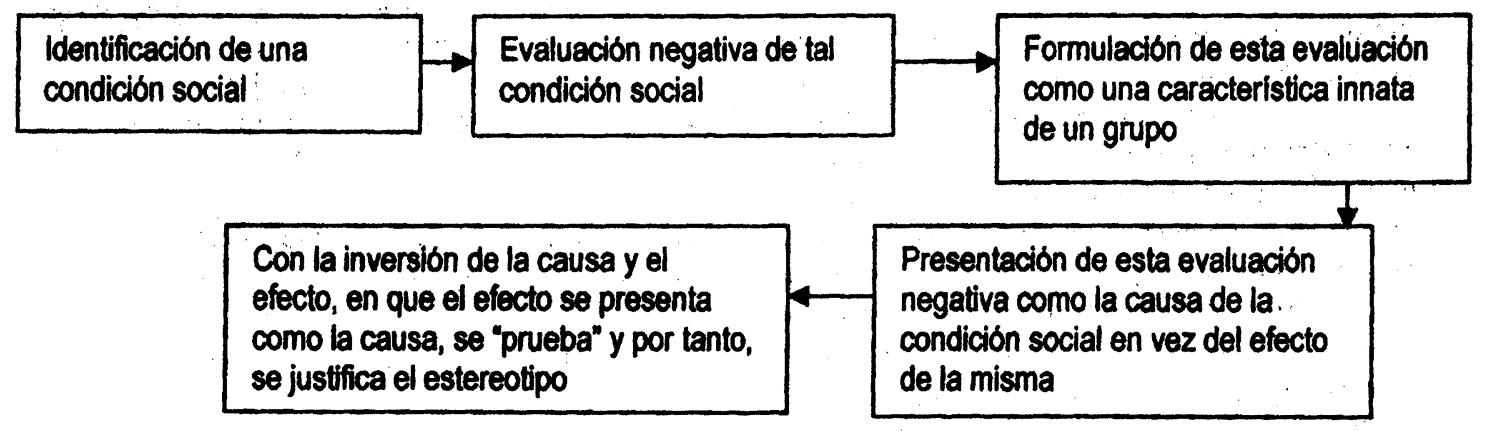

El hecho de que se identifique al grupo como perteneciente a la clase social baja, que se lo evalúe negativamente como improductivo y que se establezca esa característica como algo propio del grupo termina justificando la situación de pobreza endémica en que viven. Los demás rasgos negativos afianzan la idea de que sufren porque no hacen nada para salir de esa situación y en algunos casos hasta se desliza la creencia de que no lo hacen porque les resulta conveniente o más sencillo que luchar como lo hacen todos.

Así, los políticos de turno se benefician doblemente con la instalación del estereotipo del inundado: por un lado, mostrarse solidarios con ellos -legalizando la ocupación de tierras bajas o facilitando la creación de asentamientos, regalando alimentos o frazadas-, les asegura un cierto caudal de votos; por otro lado, en la medida en que la sociedad los responsabiliza de su propia condición, los exime de la presión de implementar cambios sustanciales que logren integrarlos al sistema productivo de la provincia.

Pero el estereotipo de los inundados no sólo nos permite racionalizar nuestra conducta en relación con ellos sino también, por analogía, con otros grupos marginales que están fuera del sistema productivo como, por ejemplo, los aborigenes.

La presencia de estereotipos es vital para construir y a la vez reforzar un sistema de convenciones sociales. Al reconocer que los 'otros' son diferentes hay un 'nosotros' que se fortalece.

Generalmente, el estereotipo se aplica a grupos que luchan por el poder político o reclaman su atención. El de los inundados es efectivo en tanto invoca un consenso, representa una opinión común acerca de un grupo social. Este consenso que invoca un estereotipo es menos real de lo que aparenta, sin embargo, se ha convertido en un concepto comunicativo corriente porque es percibido por la gente como una representación válida o verosímil.

\section{Conocimiento mediado, cultura urbana y medios masivos}

El desarrollo de Resistencia coincide con el período de mayor crecimiento de los medios de comunicación audiovisuales. A escala planetaria, el cine, primero y la televisión después irrumpieron en la escena urbana para no abandonarla jamás. El dato es relevante si consideramos que una de las mayores fuentes de mediación durante el Siglo XX fueron la prensa y la televisión. A Resistencia no le cupo la posibilidad de construir un significado social 
fuera de la intervención mediática ni fuera del proceso de industrialización que con el tiempo se impuso a América Latina. No es aventurado, entonces, afirmar que el proceso de extrañamiento del individuo respecto de su entorno natural, en Resistencia se vio fortalecido por el avance de la sociedad industrializada y por la presencia de los medios masivos de comunicación.

Muchos autores teorizaron sobre la función de los medios en la construcción de representaciones sociales y otros, incluso los consideran inseparables de la economía de mercado $^{3}$. Lo que parece incuestionable es que cada vez más, los habitantes de las ciudades nos informamos sobre cuestiones vitales -y triviales también- a través de los medios masivos. Con respecto al tema que nos ocupa, diremos que es más frecuente entre los pobladores de Resistencia enterarse de las condiciones climáticas encendiendo la radio o la televisión que observando el aspecto del cielo, la dirección de los vientos, los signos de la naturaleza. Esa actitud (opuesta a la vivencia directa de las cosas) se traslada a todas las áreas de la vida y transforman al individuo $\mathrm{y}$ a las audiencias en receptores de un tipo de información basadas en versiones de la realidad, que son tomadas, muchas veces, como si fueran la realidad.

No estamos diciendo que los medios masivos puedan ocultar una inundación o inventarla. Sólo queremos reflexionar sobre el hecho de que los desastres son altamente beneficiosos para los medios de prensa. Quizás si la mitad del espacio utilizado para mostrar las inundaciones se dedicara para educar sobre cómo prevenir sus efectos daffinos la percepción y la conducta de la población cambiaran con el tiempo.

Por otro lado, como ocurre en otras ciudades del interior del país, en Resistencia, uno de los medios periodísticos de mayor impacto en la comunidad está sufriendo una transformación que apunta al desconocimiento de la diversidad y especificidad regionales de contenidos en favor de la homogeneización del público. El único canal televisivo de aire que hasta hace poco más de cuatro años transmitía las noticias locales ha pasado a convertirse en estación repetidora de otro canal que se produce y se difunde a nivel nacional desde Buenos Aires. En este contexto que acusa nuevas prácticas monopólicas y fortalece antiguas recetas centralistas, el televidente de Resistencia que desea informarse sobre los acontecimientos de la ciudad o del Chaco es tratado como cliente de segunda categoría. Si juzgamos el horario en que se transmiten los programas que son de interés genuino para la zona es posible advertir que están sumamente alejados de las horas consideradas altamente convocantes: para acceder a un noticiario local hay que sintonizar después de las 24 .

Consideramos que la recuperación de la representación en los medios por parte de la comunidad es uno de los requisitos previos para una educación en problemas de indole ambiental que los pretenda utilizar como portavoz. La relación mediática de los individuos con su entorno no es nociva en sí misma, sino las posibilidades de manipulación o desinformación

\footnotetext{
3 Adorno, Th. y Horkheimer, M.:(1981) "La industria de la Cultura" en: Curran, J. "Sociedad y comunicación de masas"; Fondo dee Cultura Económica; México. También Adorno, Th: (1975): "Dialéctica negativa"; Taurus, Madrid; y; del mismo autor, "Televisión y cultura de masas"; Edecor; Córdoba.
} 
que comporta tal relación. Cabe agregar que a esta apreciación cualitativa debe sumársele otra de indole cuantitativa: el promedio de las horas diarias que los habitantes urbanos le dedicamos a la televisión es exorbitante.

Esta relación extremadamente mediatizada que tenemos con el contexto -no sólo natural sino cultural, social, político- es estudiada por diferentes pensadores de la sociología urbana, de la semiótica, de la ecología. Desde distintas perspectivas, lo que parece haber quedado establecido es que conforme avanza el conocimiento mediado sobre el empírico vamos perdiendo la capacidad para evaluar información proveniente del entorno y actuamos con frecuencia sobre la base de afirmaciones dadas por verdaderas sin que medie una instancia deliberativa o crítica. Perder gradualmente la capacidad para interrogarse sobre aparentes certezas, para analizar problemas complejos, para reconocer relaciones causales y realizar inferencias puede ser una especie de analfabetismo semiótico al que nos sumamos inconscientemente.

Si bien es cierto que es muy poco probable que la comunicación con el medio ambiente -un hábito milenario- pueda volver a darse en las condiciones originarias, la especie humana no puede resignar la práctica de desentrafiar significados. Recuperar la capacidad de leer el entorno, de estar atentos a las constantes y variaciones, de buscar reglas generales utilizando la experiencia de la comunidad, de establecer relaciones y de predecir su comportamiento es también una competencia necesaria para sobrevivir en la ciudad del Siglo XXI.

El desarrollo del modelo urbano imperante atiende más a la comunicación eficiente entre los espacios de producción, intercambio y consumo que a la relación armónica entre el hombre y el ambiente. No obstante, el hecho de ignorar la segunda, produce ruido al interior de la primera. La percepción cobra entonces un valor elevado en el funcionamiento de la ciudad actual: no advertir los riesgos puede significar pérdidas de vidas, de bienes, de oportunidades, de futuro.

\section{Percepción de riesgo en Resistencia}

Para analizar la percepción de riesgo seguiremos a Poggiese (1999). Respecto de las zonas anegadizas en los habitantes de Resistencia tomaremos una constante que puede expresarse de la siguiente manera: a épocas de estabilidad en la crecida de los róos corresponde una baja percepción de riesgo que se incrementa entre los pobladores y los organismos oficiales cuando las crisis ambientales se manifiestan en forma de inundaciones. Una cronología de las medidas de mitigación o prevención de los daffos coincide con la cronología de las crisis hidricas. Ello nos habla de la falta de competencia para descifrar la naturaleza de las inundaciones y para organizar el hábitat urbano teniendo presente las consecuencias a largo plazo.

Una mirada retrospectiva de la incidencia de las condiciones naturales en el poblamiento de Resistencia, nos permite reconocer por lo menos tres etapas:

Desde su fundación hasta 1966: caracterizada por un comportamiento hídrico regular, la creación y expansión de nuevos asentamientos y por la ausencia de medidas precautorias. Los llamados valles de inundación se fueron ocupando desordenadamente. Junto con la inundación 
del '66 termina esta etapa de relativa armonia entre los habitantes y la naturaleza y aparecen en escena las primeras medidas preventivas.

Desde 1966 hasta 1998: caracterizada por un importante crecimiento demográfico en el conurbano (de 8.000 a 10.000 habitantes por año); se implementan medidas tendientes a regular los emplazamientos (Código de Ordenamiento Urbano-Ambiental del Gran Resistencia y el Código de Aguas de la Provincia del Chaco); se crea el Plan de Defensa contra lás Inundaciones del Gran Resistencia; se inicia una serie de obras hídricas que incluyen defensas costeras, estaciones de bombeo, desagles cloacales, viviendas para la relocalización de inundados. En este período, las crecidas sumadas a las grandes lluvias, golpearon duramente a la ciudad (1982-1983 y 1998).

Desde 1998 hasta nuestros días: las pérdidas sufridas en la última emergencia apresuran la ejecución de programas de mayor envergadura con fondos de la Nación. La Secretaria de Recursos Naturales y Desarrollo Sustentable de la Nación llama a licitación pública nacional para la obra 'Bajos Submeridionales, canal línea Paraná'. El mismo, comprende siete proyectos que se refieren al manejo hidráulico de las líneas Tapenagá y Paraná; viviendas para relocalización de afectados, ampliación de servicio de agua potable y la adecuación hidráulica del sistema vial. Este conjunto de obras es el primer intento sistemático en pos de una solución global al problema del agua.

Lejos de ser una problemática simple, la percepción de riesgo, se vincula no sólo con una serie de competencias semióticas sino que exige la incorporación de una praxis ética. De parte de los pobladores comunes, participación y control y de los organismos oficiales (y los ciudadanos) se requiere una actitud de respeto hacia la naturaleza, la búsqueda de una mejor calidad de vida para todos, la voluntad política de hacer cumplir con las reglamentaciones vigentes (o invertir los escasos recursos en medidas de mitigación), la incorporación de estudios de impactos ambiental y social como prerrequisitos para autorizar la expansión de la ciudad; la búsqueda de un desarrollo sustentable, es decir, considerar a las futuras generaciones en la planificación de la ciudad.

\section{Conclusiones}

Dado que el Gran Resistencia por sus características geomorfológicas es proclive en alto grado a las inundaciones y que demográficamente sufre actualmente un aumento sensible de población urbana, las zonas no inundables se hacen cada vez más codiciadas. En este marco, la ubicación de los bolsones de pobreza en las áreas inundables se explica por sí sola. Ello no alcanza para explicar que los pobres eligen asentarse en esos sectores y que lo hagan ex profeso para recibir asistencia social. Eso, sencillamente, nos está hablando de un modelo de desarrollo que necesita y acepta exponer al riesgo a su población. En la comunidad de Resistencia el riesgo y el desastre tienen significados diferentes según se pertenezca a uno u otro sector social.

$\mathrm{Si}$ las inundaciones son mostradas en los medios en su etapa de emergencia sin referencia explícita a la historia, los espacios y los grupos afectados es porque el discurso de los medios sigue preso de una lógica que considera a los desastres como naturales, al modelo de desarrollo occidental como viable y deseable; a la vulnerabilidad como un efecto no deseado. La retórica que clama por solidaridad y ayuda reproduce la visión de los gobiernos y entidades de crédito: ayudar para que nada cambie. 
Proponemos que una de las posibilidades de construir el desastre desde una perspectiva plural que implique repertorios conceptuales y de acción más amplios descansa también, en la capacidad de poner en circulación otros relatos, descripciones y explicaciones de las inundaciones en los medios masivos y sobretodo, que tales discursos no se interrumpan junto con la emergencia sino que acompañen la maduración de un proceso de desarrollo local.

\section{Bibliografia.}

Administración Provincial del Agua Provincia del Chaco (1999), Resolución 1111, Resistencia. Adorno, Th. y Horkheimer, M. (1975), Dialéctica negativa, Taurus, Madrid.

- (1981), "La industria de la cultura." En Curran, J. Sociedad y comunicación de masas, Fondo de Cultura Económica; México.

- (1966), Televisión y cultura de masas, Edecor, Córdoba.

Aparici, R. (1996), La revolución de los medios audiovisuales, Ed. De la Torre. Madrid.

Atorresi, A. (1996), Los estudios semióticos. El caso de la crónica periodística. CONICET. Bs As.

Blaikie, P. (1996), Vulnerabilidad. El entorno social, politico y económico de los desastres. La RED, Bogotá.

Eco, U. (1981; edic. original 1976): Tratado de Semiótica General, Lumen; Barcelona.

Geerz, C.(1996), La interpretación de las culturas, Gedisa; Barcelona.

Lavell, A. (1994) Viviendo en riesgo: Comunidades vulnerables y prevención de desastres en América Latina. FLACSO. LA RED. CEPREDENAC. Tercer Mundo Ed., Colombia.

Lavell, A.: (2000), "Desastres y desarrollo, hacia un entendimiento de las formas de construcción social de un desastre: el caso del Huracán Mitch".

Maskrey, Andrew (1993), Los desastres no son naturales, Tercer Mundo Ed., Bogotá, Colombia.

Poggiese H. (1999) "Percepción social del riesgo. Inundaciones del arroyo Maldonado: mapa de riesgo elaborado con participación comunitaria." Seminario inundaciones en el AMBA (FADU/BM), Editado en CD (GAO: Bs. As.), Publicado en Inundaciones en el Área Metropolitana de Buenos Aires, 2001.

Quin, R. (1996), "La enseñanza de los estereotipos." En: Aparici (1996), La Revolución de los medios audiovisuales, Ed. De la Torre. Madrid.

Verón, E. (1983), Construir el acontecimiento, Gedisa, Bs. As. 